\title{
Early Developmental Low-Dose Methylmercury Exposure Alters Learning and Memory in Periadolescent but Not Young Adult Rats
}

\author{
Damaris Albores-Garcia, Leonor C. Acosta-Saavedra, Alberto J. Hernandez, \\ Miriam J. Loera, and Emma S. Calderón-Aranda \\ Departamento de Toxicología, CINVESTAV, 07360 México, DF, Mexico \\ Correspondence should be addressed to Emma S. Calderón-Aranda; scalder@cinvestav.mx
}

Received 3 August 2015; Revised 20 October 2015; Accepted 8 December 2015

Academic Editor: Lap Ho

Copyright (c) 2016 Damaris Albores-Garcia et al. This is an open access article distributed under the Creative Commons Attribution License, which permits unrestricted use, distribution, and reproduction in any medium, provided the original work is properly cited.

\begin{abstract}
Few studies have assessed the effects of developmental methylmercury ( $\mathrm{MeHg}$ ) exposure on learning and memory at different ages. The possibility of the amelioration or worsening of the effects has not been sufficiently investigated. This study aimed to assess whether low-dose $\mathrm{MeHg}$ exposure in utero and during suckling induces differential disturbances in learning and memory of periadolescent and young adult rats. Four experimental groups of pregnant Sprague-Dawley rats were orally exposed to MeHg or vehicle from gestational day 5 to weaning: (1) control (vehicle), (2) $250 \mu \mathrm{g} / \mathrm{kg} / \mathrm{day} \mathrm{MeHg}$, (3) $500 \mu \mathrm{g} / \mathrm{kg} / \mathrm{day} \mathrm{MeHg}$, and (4) vehicle, and treated on the test day with MK-801 (0.15 mg/kg i.p.), an antagonist of the N-methyl D-aspartate receptor. The effects were evaluated in male offspring through the open field test, object recognition test, Morris water maze, and conditioned taste aversion. For each test and stage assessed, different groups of animals were used. MeHg exposure, in a dose-dependent manner, disrupted exploratory behaviour, recognition memory, spatial learning, and acquisition of aversive memories in periadolescent rats, but alterations were not observed in littermates tested in young adulthood. These results suggest that developmental low-dose exposure to $\mathrm{MeHg}$ induces age-dependent detrimental effects. The relevance of decreasing exposure to MeHg in humans remains to be determined.
\end{abstract}

\section{Introduction}

Developmental exposure to environmental pollutants has been associated with the onset of cognitive disturbances, due to the sensitivity of the immature central nervous system (CNS) to external insults. Methylmercury $(\mathrm{MeHg})$ is a global pollutant with known effects on the CNS, especially when the exposure occurs at early developmental stages, as demonstrated in the Minamata and Iraq episodes [1,2]. Recently, epidemiological studies evaluated the neurocognitive outcomes of $\mathrm{MeHg}$ exposure on fish-eating populations [35] and non-fish-eating populations [6], without conclusive results. In America, $\mathrm{MeHg}$ contamination is a public health problem [7-12]; Trasande et al's study [13] suggested that the annual impact of $\mathrm{MeHg}$ exposure in the U.S. reaches nearly half a million children born with cord blood mercury levels associated with a diminishment of Intelligence Quotient (IQ), which could be detrimental to economic productivity. The possible monetary benefit of reducing $\mathrm{MeHg}$ exposure in the European population, related to IQ outcomes, has also been reported [14]. Data from experimental studies suggests that neonatal exposure to low-doses of $\mathrm{MeHg}$ is associated with visual, memory, and social alterations in nonhuman primates [15-17], memory deficits, and depressive-like behaviour in mice [18] and at higher doses $(>3,000 \mu \mathrm{g} / \mathrm{kg} /$ day $)$ severe motor dysfunction and cognitive deficits [19]. Rats, due to their toxicokinetics, must consume 10-fold higher doses of $\mathrm{MeHg}$ than humans, nonhuman primates, and mice to achieve similar brain $\mathrm{Hg}$ levels and present neurotoxic effects [20,21]. Thus, to perform an accurate interspecies comparison, it is necessary to consider the dose, exposure schedule, and toxicokinetics of the experimental model. Experimental evidence from pregnant rats exposed to daily doses of $500 \mu \mathrm{g} / \mathrm{kg}$ of $\mathrm{MeHg}$ showed that $\mathrm{MeHg}$ levels in 
the brain of pups reached concentrations in the range of $\mathrm{MeHg}$ levels found in the brains of infants from populations exposed through fish consumption [20, 22].

Severe adverse effects on learning and memory have been reported in experiments using large doses of $\mathrm{MeHg}(1,000$ to $8,000 \mu \mathrm{g} / \mathrm{kg} /$ day) and different exposure schedules in rodents [23-25]. Studies that have used doses of $\mathrm{MeHg}$ under $1,000 \mu \mathrm{g} / \mathrm{kg} /$ day have found neurocognitive effects ranging from nonexistent to subtle disturbances [18, 26-29], but few studies have evaluated the effects of $\mathrm{MeHg}$ exposure during gestation and lactation on learning and memory at different ages. Sakamoto et al. [26] found alterations in motor coordination and learning disabilities on the passive avoidance test at 5 and 6 weeks of age in rats exposed throughout gestation and until 2 months old. Kakita et al. [30] found a decrease in the neuron population of the amygdala and hippocampus but not the dentate gyrus and learning disabilities in the passive avoidance test and unaffected spatial learning in 6-month-old rats exposed to $1,000 \mu \mathrm{g} / \mathrm{kg} / \mathrm{day}$ of $\mathrm{MeHg}$ during gestation. Onishchenko et al. [18] found a decrease in reference memory and depressive-like behaviour in transgenic ARE-hPAP mice gestationally exposed to $500 \mu \mathrm{g} / \mathrm{kg} / \mathrm{day}$ of $\mathrm{MeHg}$ at 5-15 and 26-36 weeks old. Weiss et al. [31] found adverse effects on motor coordination in mice that were exposed throughout their lives to 1,000 or 3,000 $\mu \mathrm{g} / \mathrm{kg} /$ day of $\mathrm{MeHg}$. Therefore, it is important to determine whether gestational exposure to lowdoses of $\mathrm{MeHg}$ produce age-dependent effects on learning and memory, to support studies in humans and evaluate actions to reduce exposure to $\mathrm{MeHg}$ and to apply early interventions to decrease the long-term harmful effects of $\mathrm{MeHg}$.

Different types of learning and memory tasks for rodents have been used to evaluate the effects of toxicants and the participation of specific brain structures in these processes. The open field test (OFT) [32] has been used to evaluate the effect of $\mathrm{MeHg}$ on locomotor activity. The object recognition test (ORT), the Morris water maze (MWM), and conditioned taste aversion (CTA) [32-34] have been used to evaluate the potentially deleterious effects of $\mathrm{MeHg}$ on learning and memory because these experimental tools provide information about different aspects of the processes of interest. Thus, we used these tools with the aim of examining whether exposure to low-doses of $\mathrm{MeHg}$ ( 250 and $500 \mu \mathrm{g} / \mathrm{kg} /$ day) in rats during gestation and lactation was capable of inducing disturbances in learning and memory at different life stages; littermates were tested on postnatal day- (PND-) 40 (periadolescence) and on PND-90 (young adulthood). In animal models, doses that lead to $\mathrm{Hg}$ brain concentrations up to $3 \mu \mathrm{g} / \mathrm{g}$ have been referred to as low $\mathrm{Hg}$ doses [35]. The higher dose used in our study (500 $\mu \mathrm{g} / \mathrm{kg} /$ day) leads to brain concentrations of $\mathrm{Hg}$ that are below this level, according to previous reported data $[26,36]$. We used a rat model exposed to low-doses of $\mathrm{MeHg}$ from gestational day (GD) 5 to PND-21 (weaning); the offspring were exposed through the mother, by placental and milk transfer. The exposure period, doses, and administration routes were chosen to resemble the occurrence of exposures in humans during development; in addition, we used a drugtreated group (MK-801) as a positive control for detrimental effects on learning and memory; this drug is a noncompetitive antagonist of the $\mathrm{N}$-methyl D-aspartate receptor and was used because of its known effects as a performance inhibitor for all tasks tested in this study.

\section{Methods}

2.1. Animals. We used Sprague-Dawley primiparous female rats weighing 220-250 g (Harlan, Mexico), which remained in the CINVESTAV animal care facility. The rats were maintained under a light-dark cycle of $12 \mathrm{~h} /$ day, in a room with controlled temperature $\left(22^{\circ} \mathrm{C}\right)$, humidity $(45-50 \%)$, and free access to food and water. Two female rats were placed with single male rats, and vaginal smears were taken the next morning. Sixty pregnant rats were randomly assigned to eight groups and these were submitted to four experimental conditions, using two groups per experimental condition.

2.2. Chemicals. Methylmercuric chloride (methylmercury; 95\% purity) was obtained from Sigma (Sigma-Aldrich, St Louis, MO, USA). A solution of $750-1,500 \mu \mathrm{g} / \mathrm{mL}$ of $\mathrm{MeHg}$ was prepared daily in sterile deionized water. MK-801 was obtained from Sigma (Sigma-Aldrich, St Louis, MO, USA) and dissolved in sterile water.

2.3. Dosing. Pregnant rats were treated from GD-5 until weaning at PND-21; rats were weighed daily before the administration of the treatments. For control and MK-801 groups $150 \mu \mathrm{L}$ of water was orally administered; for groups exposed to $\mathrm{MeHg}$ the final volume per rat was in a range of $100-150 \mu \mathrm{L}$, which was orally administered to achieve a final dose of 250 or $500 \mu \mathrm{g} / \mathrm{kg} /$ day. MK-801 was administered prior to behavioural tasks $(0.15 \mathrm{mg} / \mathrm{kg}$, i.p. $15 \mathrm{~min}$ before the trial). Control and $\mathrm{MeHg}$-treated groups received saline solution (i.p.) $15 \mathrm{~min}$ before the trial. In dams, no evidence of toxicity, motor alterations, abortions, or general health disturbances was observed during gestation and lactation; additionally, the litter size of $\mathrm{MeHg}$ dams was not different from the control group. No differences in body weight between pups of different experimental groups were observed.

2.4. Behavioural Testing. Male pups from each group were randomly assigned to experimental subgroups. Each experimental group included a single male from each litter. The learning and memory tasks were performed at PND40 and PND-90, with 8 to 10 rats for each experimental condition (control, MK-801, MeHg $250 \mu \mathrm{g} / \mathrm{kg} / \mathrm{day}, \mathrm{MeHg}$ $500 \mu \mathrm{g} / \mathrm{kg} / \mathrm{day}$ ) (Table 1 and Figure 1). Test days for learning and memory evaluation were chosen to determine the effects of the low-dose $\mathrm{MeHg}$ exposure schedule in periadolescent (PND-40) and young adult rats (PND-90). For each test and stage assessed, different groups of animals were used. In the test room, controlled conditions were maintained for sound, light, humidity, and temperature $\left(22^{\circ} \mathrm{C}\right)$. All tests were performed in the light phase of the day (between 9 am and $3 \mathrm{pm}$ ). The order in which the animals were trained was randomized. The protocol used in this study was revised and approved by the CINVESTAV Animal Care and Use Committee, avoiding animal suffering at every stage of the experiment. 
TABLE 1: The numbers and distributions of animals for each task and evaluation times.

\begin{tabular}{|c|c|c|c|c|c|}
\hline & OFT & ORT & MWM & CTA & \\
\hline \multirow{2}{*}{ Control } & $n=10$ & $n=10$ & $n=10$ & $n=8$ & PND-40 \\
\hline & $n=10$ & $n=10$ & $n=10$ & $n=8$ & PND-90 \\
\hline \multirow{2}{*}{ MK-801 } & $n=10$ & $n=10$ & $n=10$ & $n=8$ & PND-40 \\
\hline & $n=10$ & $n=10$ & $n=10$ & $n=8$ & PND-90 \\
\hline \multirow{2}{*}{$\mathrm{MeHg} 250 \mu \mathrm{g} / \mathrm{kg} /$ day } & $n=10$ & $n=10$ & $n=10$ & $n=8$ & PND-40 \\
\hline & $n=10$ & $n=10$ & $n=10$ & $n=8$ & PND-90 \\
\hline \multirow{2}{*}{$\mathrm{MeHg} 500 \mu \mathrm{g} / \mathrm{kg} / \mathrm{day}$} & $n=10$ & $n=10$ & $n=10$ & $n=8$ & PND-40 \\
\hline & $n=10$ & $n=10$ & $n=10$ & $n=8$ & PND-90 \\
\hline
\end{tabular}

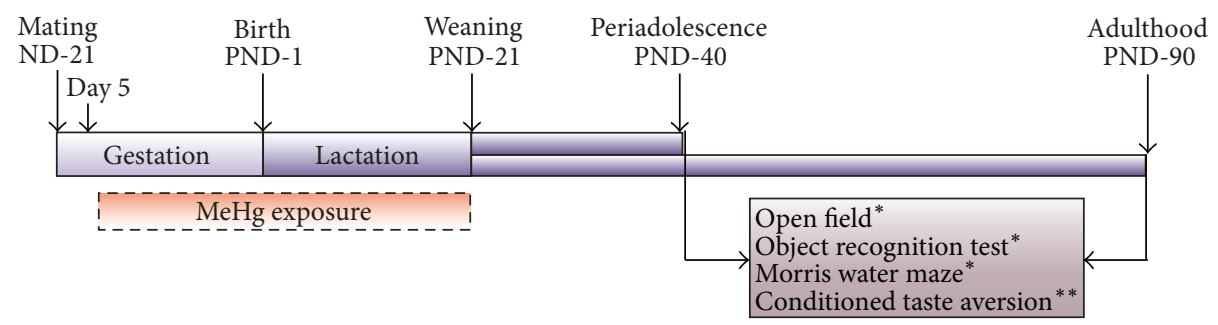

FIGURE 1: Experimental design. Pregnant rats were orally exposed to $\mathrm{MeHg}$ ( 250 or $500 \mu \mathrm{g} / \mathrm{kg} /$ day) from gestational day (GD) 5 to weaning (postnatal day- (PND-) 21). All exposure to MeHg was stopped after weaning. The learning and memory tasks were performed at PND-40 (periadolescence) and PND-90 (young adulthood), using a different cohort of rats for each task and evaluation time. ${ }^{*} n=10$ per experimental group; ${ }^{* *} n=8$ per experimental group.

2.5. Open Field Test. The test was conducted as described in the literature [32] with minor modifications. The open field consisted of a square arena $(60 \mathrm{~cm} \times 60 \mathrm{~cm})$, surrounded by $40 \mathrm{~cm}$ high white walls. Ten rats from each experimental condition were evaluated at PND-40, and a different cohort was evaluated at PND-90. The test began by placing a single rat in the middle of the arena, and its activity was recorded for $5 \mathrm{~min}$. Test session recordings were analysed offline using Any-Maze software (Stoelting, USA). The field was carefully cleaned with $70 \%$ ethanol between each rat. The parameters analysed to evaluate locomotor activity in the open field were total distance travelled and number of rearings.

2.6. Object Recognition Test. The test was performed as described in the literature [37] with minor changes. Ten rats from each group were evaluated at PND-40, and a different cohort was evaluated at PND-90. Each rat was allowed to explore the empty cage for $5 \mathrm{~min}$ for five consecutive days before the test. On the test day, each rat was placed in a cage $(60 \times 60 \mathrm{~cm})$ with a black floor. The objects to be discriminated were cubes, pyramids, and cylinders, all made from the same material and immovable when located in the field. The test consisted of two trials with a rest period of 90 min between trials. In the first trial $(5 \mathrm{~min})$, there were two identical objects in opposite corners of the cage. In the second trial, one new object replaced one of the objects that had been previously shown, and the rat was allowed to explore the object for $5 \mathrm{~min}$. The order of presentation of the objects and their corner location were counterbalanced to avoid bias. These two trials were recorded, and the exploration time for each object was subsequently analysed with AnyMaze software (Stoelting, USA). Exploration was defined as directing the nose toward the object from a distance of $2 \mathrm{~cm}$ or closer or touching the object. The recognition index (RI) was used as a measure of the ability of the animal to distinguish new objects from familiar objects and reflected the time that the animal explored the new object compared with the total exploration time.

2.7. Morris Water Maze. To analyse spatial memory using the MWM, 10 rats from each experimental condition were evaluated at PND-40, and different groups were used for assays on PDN 90. The task was performed as described in the literature [33] with minor modifications (5 training sessions, 10 assays per day) in a circular tank $(180 \mathrm{~cm}$ diameter $\times 70 \mathrm{~cm}$ height) filled with water $\left(22^{\circ} \mathrm{C}\right)$ to a depth of $40 \mathrm{~cm}$. The pool was divided into four quadrants, and the platform was located in the middle of the west quadrant, $2 \mathrm{~cm}$ below the water level. Each animal was given $60 \mathrm{sec}$ to find the hidden platform, and if it failed, it was gently guided to the platform and was allowed to remain there for $30 \mathrm{sec}$. After that, rats were toweldried and kept in holding cages for $30 \mathrm{sec}$ between trials. Different distant cues around the room were kept in the same location during the experiments. The retention test, without the hidden platform, was performed one week after the last training session, releasing the animal from a random start position. All trials were recorded on video for further analysis (Any-Maze, Stoelting, USA) to obtain the swim path, average speed, total distance travelled, and the number of crossings over the platform area. Training curve data were normalized 
TABLE 2: The effects of developmental exposure to MeHg on learning and memory in periadolescent and young adult rats.

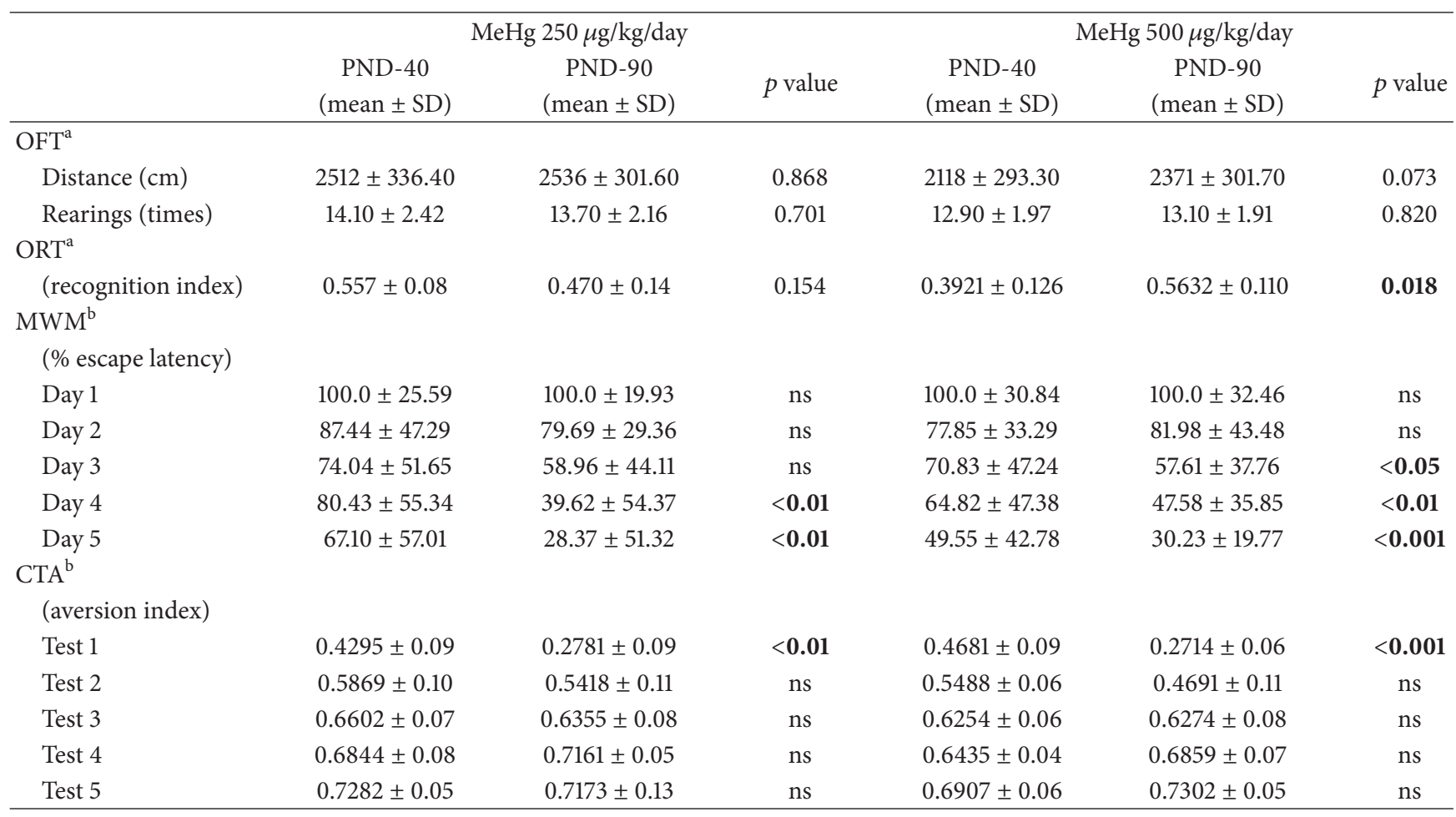

OFT: open field test; ORT: object recognition test; MWM: Morris water maze; CTA: conditioned taste aversion.

${ }^{\mathrm{a}}$ Results from one-way ANOVA; ${ }^{\mathrm{b}}$ Results from two-way ANOVA.

using the first day latency as $100 \%$ for each experimental group.

2.8. Conditioned Taste Aversion. CTA was performed as described in the literature [34] with minor modifications. A group of rats $(n=8)$ from each experimental condition was used for CTA assessment at PND-40, and different groups were used for assays at PND-90. The protocol started with water deprivation $24 \mathrm{~h}$ prior to the training. After that, the animals received tap water in their home cages every $24 \mathrm{~h}$ for $15 \mathrm{~min}$, and the amount that the animals consumed was measured. When animals reached a stable water consumption (referred to as baseline consumption), they received an acquisition trial; on this day, a new flavour was presented (saccharin 0.1\%, Sigma, Mexico), and 15 min after they drank the novel flavour, a malaise-inducing drug was administered i.p. (lithium chloride, $\mathrm{LiCl}, 0.15 \mathrm{M}, 7.5 \mathrm{~mL} / \mathrm{kg}$, Baker, Mexico). For the following two days, baseline intake of tap water was reestablished, and for the next five days, animals received saccharin $(15 \mathrm{~min})$ followed by water $(15 \mathrm{~min})$; these experimental days are represented as Test 1 to Test 5. Data from these experiments are represented by the aversion index (AI), which is a ratio that reflects the amount of saccharin ingested relative to the total liquid intake of the day $(1.0=$ saccharin + water).

2.9. Statistical Analysis. Data reported in the text and figures indicate the mean \pm SEM. For the OFT and ORT analyses, one-way ANOVA followed by Bonferroni post hoc tests was performed. For MWM and CTA we used two-way ANOVA, using the factors treatment and time (days), followed by Bonferroni post hoc tests. Differences were considered statistically significant if the $p$ value was less than 0.05 . Data analyses were performed using the GraphPad Prism 5.0 software (GraphPad Software, Inc., San Diego, CA) and all analyses were performed offline by an observer who was blinded to the treatments.

\section{Results}

3.1. Methylmercury Exposure Subtly Alters Spontaneous Activity. To evaluate changes in locomotor behaviour, we used the OFT. The data obtained showed no changes in locomotor activity (evaluated as total distance travelled) in both groups of $\mathrm{MeHg}$-exposed rats compared to the control group, assessed at PND-40 and at PND-90 (Figures 2(a) and 2(c) and Table 2). However, differences in locomotor activity between $\mathrm{MeHg}$-treated groups were observed at PND-40 ( $p<0.05,95 \%$ confidence interval (CI): 14.2-774) (Figure 2(a)) but were not observed in animals assessed at PND-90 (Figure 2(c)). The group exposed to $250 \mu \mathrm{g} / \mathrm{kg} / \mathrm{day}$ of $\mathrm{MeHg}$ did not differ from the control group in vertical exploration (rearings) at the two assessed times (Figures 2(b) and $2(\mathrm{~d})$ ). In contrast, the group exposed to $500 \mu \mathrm{g} / \mathrm{kg} / \mathrm{day}$ of $\mathrm{MeHg}$ demonstrated a diminishment in vertical exploration compared to the control group ( $p<0.05$, 95\% CI: $0.6-$ 5.5) at PND-40 (Figure 2(b)), which was not observed in 


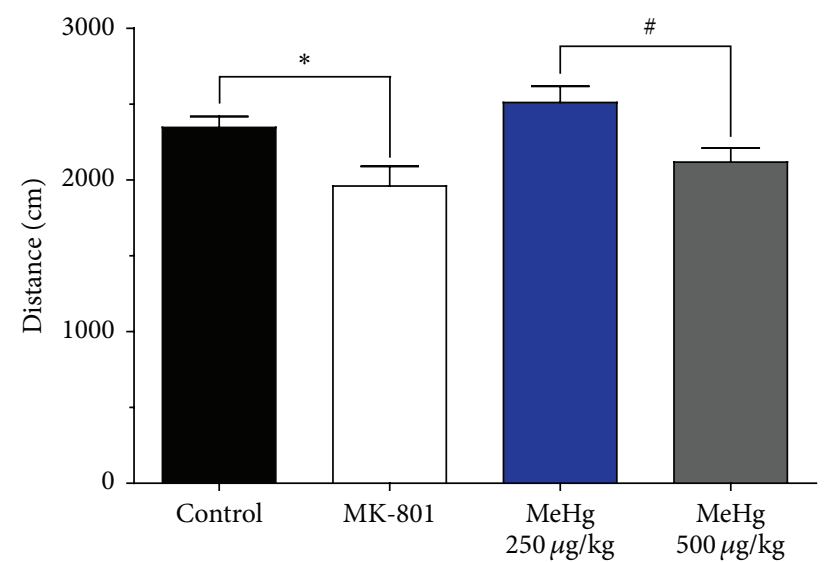

(a)

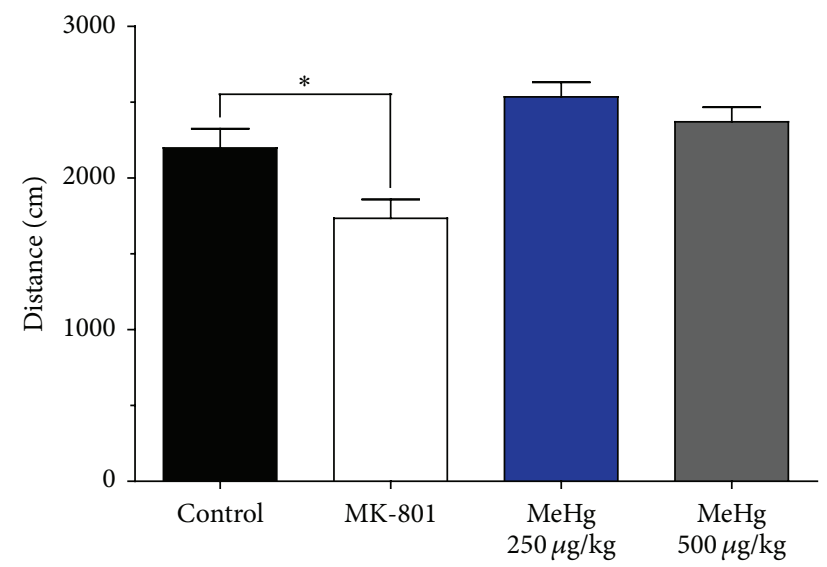

(c)

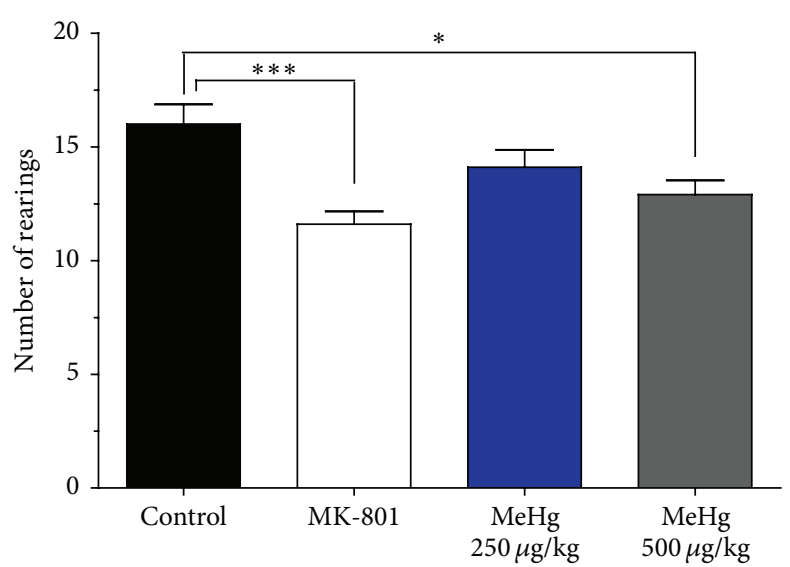

(b)

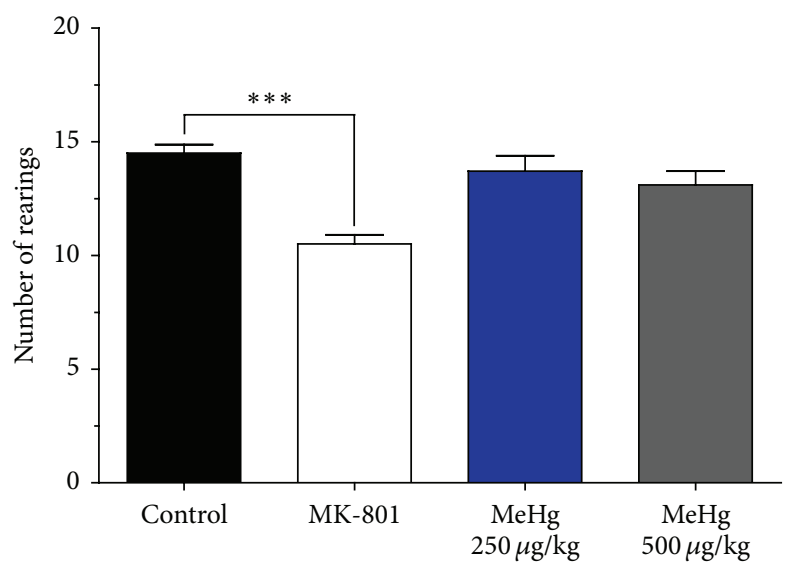

(d)

FIGURE 2: The effects of methylmercury on locomotor and exploratory behaviour. OFT was performed at PND-40 (a-b) and PND-90 (c-d). Graphs (a) and (c) show the total distance travelled (cm), and graphs (b) and (d) show the number of rearings (mean \pm SEM) at PND-40 and PND-90, respectively. The data were analysed using one-way ANOVA followed by Bonferroni post hoc tests. Significant differences compared with the control group $\left({ }^{*} p<0.05 ;{ }^{* * *} p<0.001\right)$ or with the group exposed to $250 \mu \mathrm{g} / \mathrm{kg} / \mathrm{day} \mathrm{MeHg}\left({ }^{*} p<0.05\right)$ are indicated.

animals evaluated at PND-90 (Figure 2(d)), but there were no differences between PND-40 and PND-90 in the two MeHgexposed groups (Table 2). The group treated with MK-801 was found to have a diminishment in locomotor activity $(p<$ 0.05, 95\% CI: 31.8-741.1 for PND-40 and 76.7-850.5 for PND90 ), as well as a decrease in the number of rearings at the two evaluated ages ( $p<0.001,95 \%$ CI: 1.9-7.2 for PND-40 and 2.0-6.0 for PND-90). Table 3 shows the $F$-statistic and $p$ values from one-way ANOVA analyses for OFT at PND-40 and PND-90.

\subsection{Methylmercury Exposure Impaired Short-Term Object} Recognition Memory. To evaluate object recognition memory by ORT, the RI was used as a measure of performance. The RI reflected the object exploration by the animal; RI values above 0.5 indicated that the animal spent more time with the novel object (normal performance of a rodent); a value of 0.5 indicated that the animal spent the same amount of time exploring both objects (novel and familiar), and values below
0.5 indicated that the animal spent more time exploring the familiar object.

The RI indicated that $\mathrm{MeHg}$ exposure impaired recognition memory in a dose-dependent manner in animals assessed at PND-40 (Figure 3(a)); this decrement in the RI was statistically significant in the rats exposed to $500 \mu \mathrm{g} / \mathrm{kg} /$ day of $\mathrm{MeHg}$ compared to the control group ( $p<$ $0.001,95 \%$ CI: $0.089-0.21)$ and compared to the group exposed to $250 \mu \mathrm{g} / \mathrm{kg} / \mathrm{day}$ of $\mathrm{MeHg}(p<0.05$, 95\% CI: 0.0270.30 ). In the groups assessed at PND-90, no differences were observed between the MeHg-exposed animals and control animals or between $\mathrm{MeHg}$-exposed groups (Figure 3(b)). The rats treated with MK-801 showed a statistically significant decrement in the RI compared to the control group at PND40 ( $p<0.01,95 \%$ CI: $0.057-0.32)$ and at PND-90 ( $p<0.05$, 95\% CI: $-0.33-0.02)$. Table 3 shows the $F$-statistics and $p$ values from one-way ANOVA analyses for the ORT at PND40 and PND-90.

The time-course analyses between same-dose treatments did not indicate differences in RI for the $250 \mu \mathrm{g} / \mathrm{kg} / \mathrm{day}$ 
TABLE 3: F-statistics and $p$ values from statistical analyses for the OFT, ORT, MWM, and CTA in periadolescent (PND-40) and young adult rats (PND-90).

\begin{tabular}{|c|c|c|c|c|}
\hline \multirow{2}{*}{ Task } & \multicolumn{2}{|c|}{ PND-40 } & \multicolumn{2}{|c|}{ PND-90 } \\
\hline & $F$-statistic & $p$ value & $F$-statistic & $p$ value \\
\hline OFT $^{\mathrm{a}}$, distance & $F_{3,36}=5.7$ & 0.0027 & $F_{3,36}=9.6$ & $<0.0001$ \\
\hline $\mathrm{OFT}^{\mathrm{a}}$, rearings & $F_{3,36}=6.8$ & 0.0009 & $F_{3,36}=10.6$ & $<0.0001$ \\
\hline ORT $^{\mathrm{a}}$ & $F_{3,36}=9.9$ & 0.0002 & $F_{3,36}=4.5$ & 0.0095 \\
\hline \multicolumn{5}{|l|}{$\mathrm{MWM}^{\mathrm{a}}$} \\
\hline Control & $F_{4,45}=11.32$ & $<0.0001$ & $F_{4,45}=17.31$ & $<0.0001$ \\
\hline MK-801 & $F_{4,45}=0.7188$ & 0.5841 & $F_{4,45}=1.997$ & 0.1134 \\
\hline MeHg $250 \mu \mathrm{g} / \mathrm{kg} /$ day & $F_{4,45}=0.6753$ & 0.6126 & $F_{4,45}=18.71$ & $<0.0001$ \\
\hline $\mathrm{MeHg} 500 \mu \mathrm{g} / \mathrm{kg} /$ day & $F_{4,45}=1.641$ & 0.1858 & $F_{4,45}=6.344$ & 0.0004 \\
\hline \multicolumn{5}{|l|}{$\mathrm{MWM}^{\mathrm{b}}$} \\
\hline Interaction & $F_{12,1880}=6.521$ & $<0.0001$ & $F_{12,1880}=11.47$ & $<0.0001$ \\
\hline Time & $F_{4,1880}=73.20$ & $<0.0001$ & $F_{4,1880}=252.8$ & $<0.0001$ \\
\hline Treatments & $F_{4,1880}=73.63$ & $<0.0001$ & $F_{4,1880}=26.11$ & $<0.0001$ \\
\hline \multicolumn{5}{|l|}{$\mathrm{CTA}^{\mathrm{b}}$, aversion index } \\
\hline Interaction & $F_{12,112}=1.004$ & 0.4507 & $F_{12,112}=1.95$ & 0.0357 \\
\hline Time & $F_{4,112}=53.70$ & $<0.0001$ & $F_{4,112}=307$ & $<0.0001$ \\
\hline Treatments & $F_{3,112}=13.60$ & $<0.0001$ & $F_{3,112}=1.21$ & 0.3258 \\
\hline
\end{tabular}

OFT: open field test; ORT: object recognition test; MWM: Morris water maze; CTA: conditioned taste aversion.

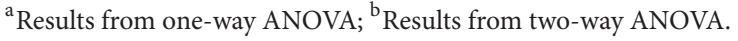

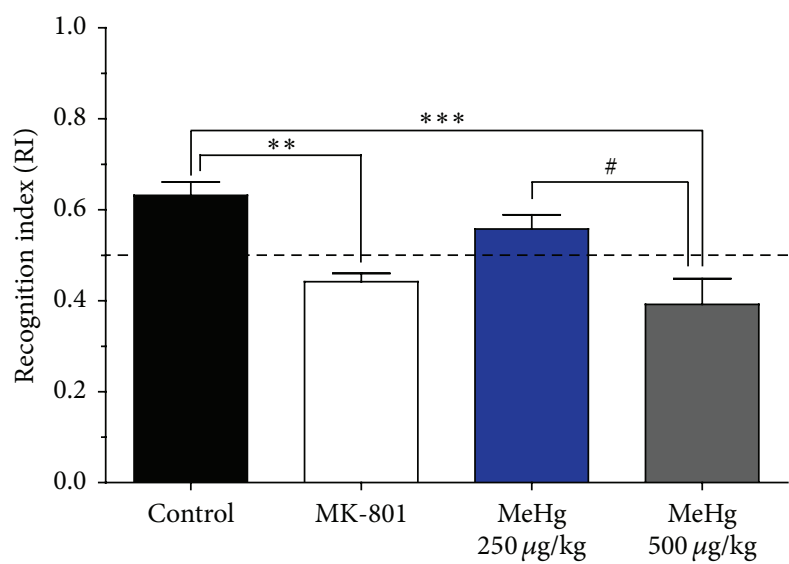

(a)

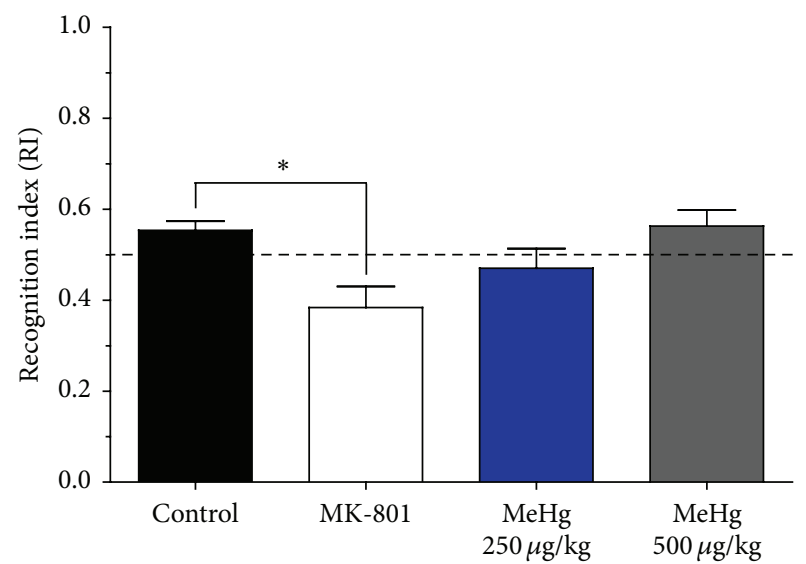

(b)

Figure 3: Methylmercury exposure disrupted recognition memory. ORT was performed at PND-40 (a) and PND-90 (b). The graphs show the recognition index (RI: time exploring new object/total exploration time) as the mean \pm SEM; an RI below 0.50 indicates that the animal spent more time exploring the familiar object, and an RI above 0.50 indicates that the animal spent more time exploring the new object. The results were analysed using one-way ANOVA and Bonferroni post hoc tests. Significant differences compared with the control group $\left({ }^{*} p<0.05 ;{ }^{* *} p<0.01 ;{ }^{* * *} p<0.001\right)$ or with the group exposed to $250 \mu \mathrm{g} / \mathrm{kg} / \mathrm{day} \mathrm{MeHg}\left({ }^{*} p<0.05\right)$ are indicated.

MeHg-treated group at the two developmental windows studied (Table 2). However, the group exposed to $500 \mu \mathrm{g} / \mathrm{kg} /$ day was found to have significant differences in RI between PND40 and PND-90. Specifically, the RI was higher at PND-90 than at PND-40. This finding indicates that the detrimental effect on recognition memory found at PND-40 (RI was significantly lower than the RI of the control group) was not detected in animals tested at PND-90 (Table 2).
3.3. Methylmercury Exposure Altered Spatial Learning. The MWM task reflected the capacity of the animal for spatial learning, exhibited in the rats' undirected swimming in the initial trials and rapid and precise swimming to the hidden platform in the later trials. Training curve data were normalized using the first day latency as $100 \%$ for each experimental group because the $\mathrm{MeHg}$-treated rats trained at PND40 found the hidden platform faster than control animals; 


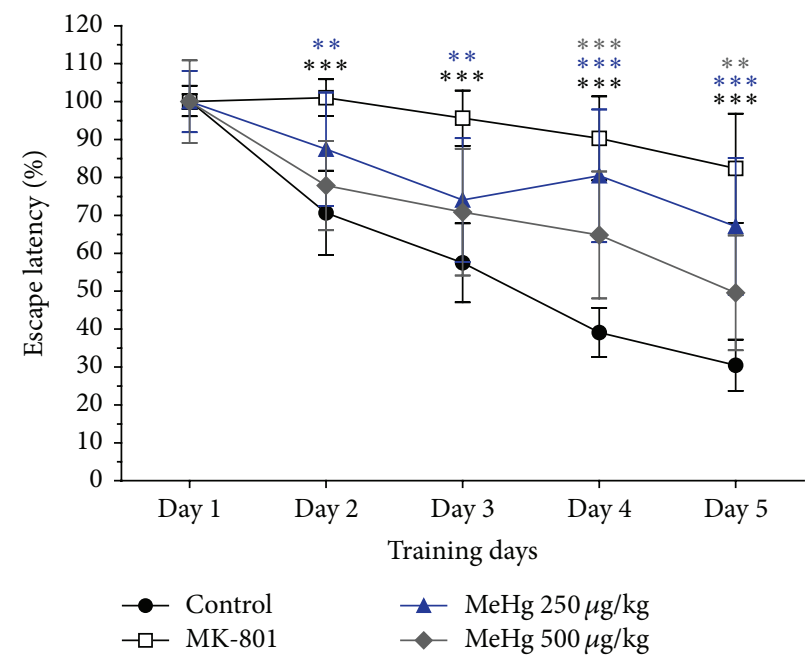

(a)

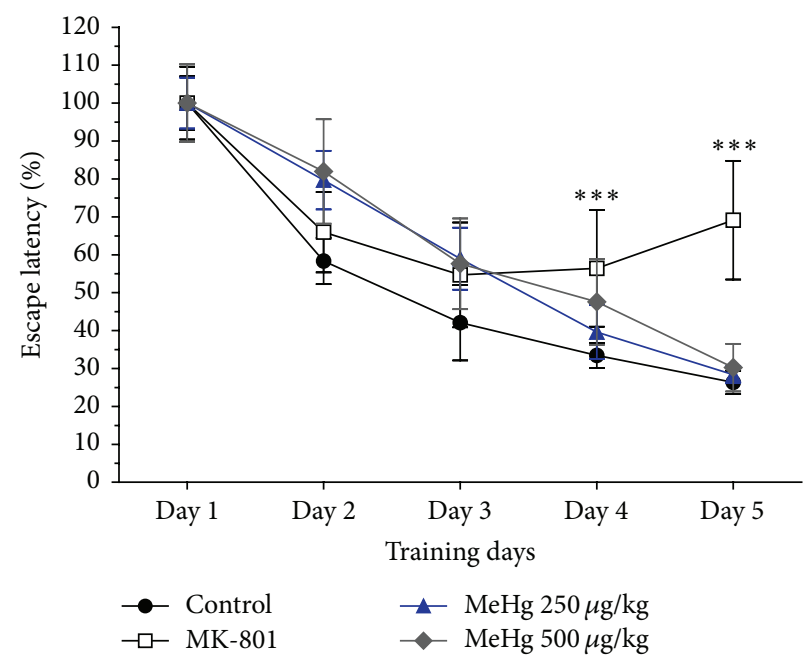

(b)

FIGURE 4: Methylmercury exposure altered spatial learning. Graphs show the learning curve normalized as a percentage of the latency of the group on the first day of training (mean \pm SEM) at PND-40 (a) and PND-90 (b). Escape latency results were analysed using two-way ANOVA, followed by Bonferroni post hoc tests; statistically significant differences compared with the control group are indicated $\left({ }^{* *} p<0.01\right.$; $\left.{ }^{* * *} p<0.001\right)$.

however, on the following days, the MeHg-treated animals did not improve their performance. The faster finding of the hidden platform on training day 1 at PND-40 was attributable to faster swimming of MeHg-treated animals (data not shown). The nonnormalized learning curve is shown in supplementary Figure 1 (see Supplementary Material available online at http://dx.doi.org/10.1155/2016/6532108).

Figure 4 shows the normalized learning curve for control and treated animals day by day, grouping the 10 trials per day for all of the individuals in each group $(n=10)$ trained at PND-40 or at PND-90. For groups assessed at PND-40, the normalized escape latency of control animals started at $100 \%$ on day 1 and reached $30 \%$ on day 5 . Significant differences between the control group and the $250 \mu \mathrm{g} / \mathrm{kg} /$ day $\mathrm{MeHg}$-exposed group were found from days 2 through 5 of training $(p<0.01$ for days 2 and 3, 95\% CI: 1.1-32.5 and $0.8-32.3$ for days 2 and 3, resp., and $p<0.001$ for days 4 and 5, 95\% CI: $25.6-57.0$ and 20.9-52.3 for days 4 and 5 , resp.). The group exposed to $500 \mu \mathrm{g} / \mathrm{kg} / \mathrm{day}$ of $\mathrm{MeHg}$ was found to have significant differences on training days 4 and 5 compared to the control group $(p<0.001,95 \% \mathrm{CI}$ : 10.0-41.4 for day $4 ; p<0.01,95 \%$ CI: $3.4-34.8$ for day 5) (Figure 4(a)). The MK-801-treated group exhibited a longer normalized escape latency during training days 2 through 5 ( $p<0.001,95 \%$ CI: 14.2-46.4, 22.0-54.2, 35.0-67.3, and 35.8-68.0 for days 2, 3, 4, and 5, resp.), which reflected the inability of the animals to learn the task when the NMDAR antagonist was administered at this age (Figure 4(a)). The analysis of within-group differences over time reflects that at PND-40, only control rats learned the task. MK-801treated animals and both $\mathrm{MeHg}$-exposed groups showed no significant differences in normalized escape latency across the five training days, reflecting the inability of these animals to learn the task (supplementary Figure 2).
In groups trained at PND-90, the rats exposed to 250 and $500 \mu \mathrm{g} / \mathrm{kg} /$ day of $\mathrm{MeHg}$ showed no significant differences in normalized escape latency compared to the control group. The MK-801-treated group exhibited a significantly slower learning process than the control group ( $p<0.001,95 \% \mathrm{CI}$ : 7.9-37.9 and 27.8-57.8 for days 4 and 5, resp.) (Figure 4(b)). The analysis of differences over time within groups indicates that, in animals trained at PND-90, control rats learned the task by the second day of training ( $p<0.01$, 95\% CI: $12-$ $71)$; rats exposed to $250 \mu \mathrm{g} / \mathrm{kg} /$ day of $\mathrm{MeHg}$ learned the task by the third day of training ( $p<0.01,95 \% \mathrm{CI}: 12.5-70)$; rats exposed to $500 \mu \mathrm{g} / \mathrm{kg} / \mathrm{day}$ of $\mathrm{MeHg}$ learned the task by the fourth day of training ( $p<0.05$, 95\% CI: 6.5-98.3); MK-801treated animals did not learn the task (supplementary data). This finding suggests that $\mathrm{MeHg}$ exposure subtly disrupts learning acquisition or memory retrieval assessed at PDN 90. No differences were found for the retention test that was performed one week after the last training session (data not shown). Table 3 shows the $F$-statistics and $p$ values from twoway ANOVA analyses for MWM at PND-40 and PND-90.

The time-course analyses for the MeHg $250 \mu \mathrm{g} / \mathrm{kg} /$ day groups indicated significant differences at test days 4 and 5 between the PND-40 and PND-90 groups. Thus, the detrimental effects on spatial learning detected in the group evaluated at PND-40 were not detectable in the group evaluated at PND-90. In the $500 \mu \mathrm{g} / \mathrm{kg} /$ day $\mathrm{MeHg}$-treated groups, the statistical analyses of escape latency at the two developmental windows studied showed that effects presented at test days 3 through 5 in the group evaluated at PND-40 were not presented in animals evaluated at PND-90 (Table 2).

3.4. Methylmercury Exposure Disturbed Acquisition and Extinction of Aversive Memories. The CTA task evaluates the acquisition and extinction of aversive memories, as assessed 


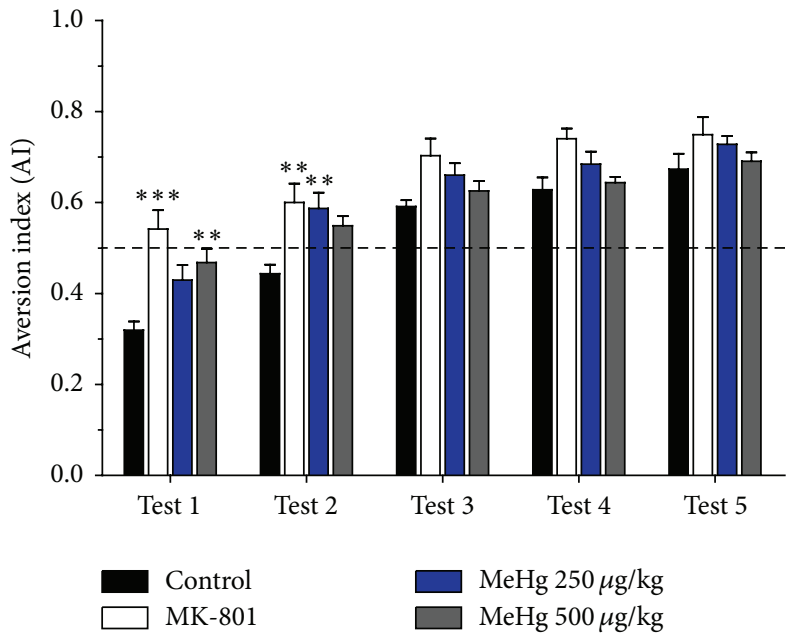

(a)

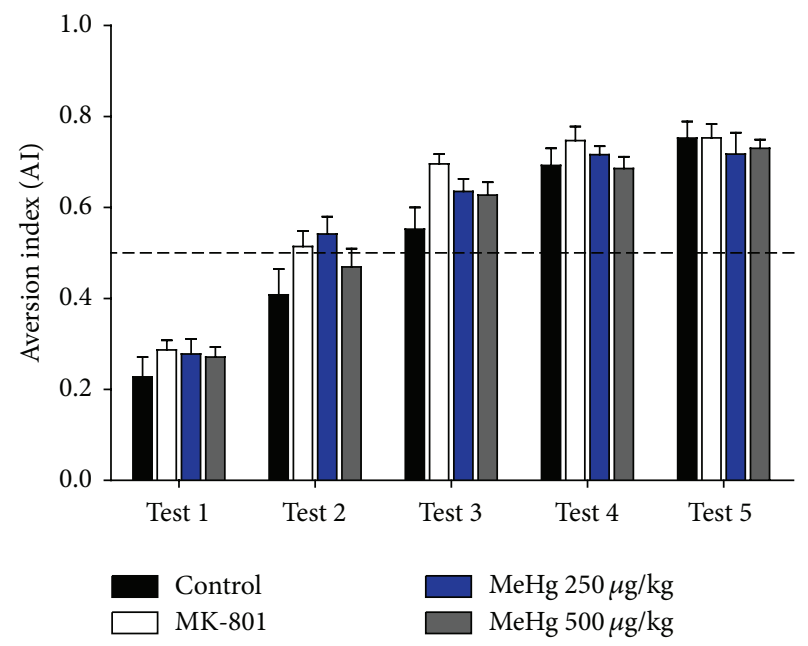

(b)

FIGURE 5: Methylmercury exposure disturbed the acquisition of aversive memories. The aversion index (AI) (mean \pm SEM) of rats at PND-40 (a) and PND-90 (b). The data were analysed using two-way ANOVA followed by Bonferroni post hoc tests; significant differences compared with the control group are indicated $\left({ }^{* *} p<0.01 ;{ }^{* * *} p<0.001\right)$.

by the AI. Water deprivation did not affect the body weights of the animals (data not shown). In animals assessed at PND-40, the control group had an AI of 0.3 on test day 1 , which reflects aversion to saccharin (Figure 5(a)). The MK-801-treated animals had an $\mathrm{AI}$ of 0.54 , indicating greater consumption of saccharin than the control group ( $p<0.001,95 \%$ CI: $0.07-$ 0.3 ), representing no aversion to saccharin on Test 1 . Animals exposed to $250 \mu \mathrm{g} / \mathrm{kg} /$ day of $\mathrm{MeHg}$ demonstrated a slight increase in saccharin consumption (AI of 0.43), whereas animals exposed to $500 \mu \mathrm{g} / \mathrm{kg} /$ day of $\mathrm{MeHg}$ did not decrease saccharin intake (AI of $0.47, p<0.01,95 \%$ CI: $0.02-0.27$ ), reflecting no acquisition of aversion (Figure 5(a)).

In animals assessed at PND-90, no significant differences in AI were observed between groups on tests 1 through 5 (Figure 5(b)), indicating that, at this age, there was no effect of $\mathrm{MeHg}$ treatment on the acquisition of aversive memories. Table 3 shows the $F$-statistics and $p$ values from two-way ANOVA analyses for CTA at PND-40 and PND-90.

The time-course analyses for the $250 \mu \mathrm{g} / \mathrm{kg} / \mathrm{day} \mathrm{MeHg}$ treated groups indicated significant differences on Test 1 , but none of those groups (PND-40 and PND-90) were different from their respective control. At PND-40, rats exposed to $250 \mu \mathrm{g} / \mathrm{kg} /$ day of $\mathrm{MeHg}$ showed a slight, but not significant, preference for saccharin, suggesting no aversion. In contrast, animals assessed at PND-90 demonstrated an aversion to saccharin consumption (Table 2).

The time-course analyses for MeHg $500 \mu \mathrm{g} / \mathrm{kg} /$ day indicated significant differences on Test $1(p<0.001)$ between the two assessed ages. Moreover, in this case the AI at PND40 was significantly higher than that of the control group, which indicates no aversion to saccharin (Table 2) or a poor CTA acquisition. In contrast, the animals assessed at PND-90 demonstrated an aversion to saccharin, which indicates the acquisition of CTA.

\section{Discussion}

Despite knowledge of the adverse effects on the CNS caused by exposure to high doses of $\mathrm{MeHg}$, there is a gap in knowledge of the detrimental effects of low and continual $\mathrm{MeHg}$ exposure during gestation and early postnatal life. The majority of studies evaluated the outcomes at one developmental stage, in some cases finding effects that were not assessed later in life, leaving as an open possibility the amelioration or worsening of the observed effects.

Epidemiological studies conducted in fish-eating populations have suggested that low and continual $\mathrm{MeHg}$ exposure could lead to behavioural outcomes $[4,5,38]$. Information on the possible adverse cognitive and behavioural effects of lowdose $\mathrm{MeHg}(500-1,000 \mu \mathrm{g} / \mathrm{kg} /$ day) exposure is limited; the available findings are not conclusive, though these findings suggest a broad range of behavioural alterations including depressive-like behaviour [18].

Therefore, the study of exposure to environmentally relevant doses of $\mathrm{MeHg}$ is of special interest; the present study focused on the effects of this type of exposure from gestation through weaning on learning and memory and possible differential age effects. This study showed that early developmental exposure to doses of $500 \mu \mathrm{g} / \mathrm{kg} / \mathrm{day}$ of $\mathrm{MeHg}$ impaired exploratory behaviour, recognition memory, spatial learning, and aversive memories in periadolescent rats but not young adult rats. These findings could be explained by several factors such as the following: (a) the $\mathrm{MeHg}$ dose received by the pups was not sufficient to cause longlasting adverse effects and compensatory systems could act to overcome the detrimental effects observed at PND-40; (b) the effects observed at PND-40 may be due to alterations in neurotransmission or synaptogenesis; (c) the younger CNS is more vulnerable to detrimental effects of $\mathrm{MeHg}$. 
Results from the OFT in periadolescent and young adult rats suggest that, at the doses and the exposure schedule used, $\mathrm{MeHg}$ did not induce detectable locomotor deficits in the offspring, which is consistent with the literature [18]. However, the locomotor activity of the group of rats that was exposed to $500 \mu \mathrm{g} / \mathrm{kg} / \mathrm{day}$ of $\mathrm{MeHg}$ was lower than the activity of the group that was exposed to $250 \mu \mathrm{g} / \mathrm{kg} /$ day of $\mathrm{MeHg}$, which suggests that a slightly higher dose than the dose used in this study might produce locomotor effects under our exposure protocol.

In the group that was exposed to $500 \mu \mathrm{g} / \mathrm{kg} / \mathrm{day}$ of $\mathrm{MeHg}$, there was significant impairment in exploratory behaviour (rearings) on PND-40 but not on PND-90. The data from PND-40 are consistent with the literature $[39,40]$, and the age-dependent nature of the effect suggests a subtle alteration in the cerebellum, which is not strong enough to remain after the exposure is discontinued, when compensatory mechanisms could counteract the effect. $\mathrm{MeHg}$ has been reported to impair glutamatergic signalling in cerebellar granule cells [41], which could explain the alterations observed in exploratory behaviour.

In the animals assessed at PND-40, MeHg exposure had a dose-dependent effect on recognition memory. However, in the animals assessed at PND-90, no significant differences were detected for any dose of $\mathrm{MeHg}$ compared to the control group. In this regard, the potential detrimental effects of prenatal low-dose $\mathrm{MeHg}$ exposure are controversial. The epidemiological evaluation of the effects of prenatal $\mathrm{MeHg}$ exposure has been related to attention impairments in Faroese and Nunavik children [38, 42-44]. Moreover, in a U.S. cohort, visual recognition memory scores were improved in the infants of women who had higher levels of fish consumption, but the scores were lower when they were adjusted for hair mercury levels above $1,200 \mu \mathrm{g} / \mathrm{kg}$ [45]. In contrast, visual recognition memory was not affected by prenatal $\mathrm{MeHg}$ in a Seychelles cohort of children evaluated at different ages $[46,47]$. However, subsequent studies of the same cohort did not refute the later presence of delayed adverse effects in these children, possibly due to a restart of the exposure or the adjustment for relevant confounders [48]. These epidemiological and experimental findings confirm the complexity of prenatal MeHg exposure and the onset of cognitive effects.

Remarkably, the MWM data indicated that exposure to both doses of $\mathrm{MeHg}$ impaired spatial learning in animals trained at PND-40, but not in animals trained at PND-90. However, the normalized learning curve of the exposed animals was slower than that of control rats. These data suggest that exposure to doses as low as $250 \mu \mathrm{g} / \mathrm{kg} /$ day of $\mathrm{MeHg}$ during CNS development impairs the acquisition of spatial learning, without abolishing the learning process. These findings suggest that early developmental exposure to low-doses of $\mathrm{MeHg}$ could be detrimental to the acquisition process, as demonstrated by the learning curve of the animals exposed to $\mathrm{MeHg}$. The hippocampus plays a central role in correct performance on the MWM, and hippocampal vulnerability to $\mathrm{MeHg}$ has been reported at low-dose exposure $(600 \mu \mathrm{g} / \mathrm{kg}$, PND-7), yielding reduced hippocampal neurogenesis and consequent memory disturbances in adolescent rats [49]. It is interesting that the MWM learning curve observed by
Sokolowski et al. [49] did not suggest a learning deficit per se but did insinuate a learning disadvantage. This result is in agreement with our finding that, at young adulthood, the MeHg-exposed animals learned the task but at a slower rate than control animals. Experimental evidence for the effects of $\mathrm{MeHg}$ on spatial learning is contradictory [24, 40,50], and it is difficult to compare across studies due to broad differences in the schedules of exposure and administered doses.

To our knowledge, this is the first study to assess the possible effect of $\mathrm{MeHg}$ on aversive memories. The CTA is assessed based on the conduct exhibited by the animal when it is challenged with a new taste; when the new flavour (conditioned stimulus) is associated with an ailment (unconditioned stimulus), the animal should develop an aversion to this flavour, and the animal should reject consumption of this flavour when it is presented again [51]. The brain structures involved in taste memory are the insular cortex $[52,53]$ and the amygdala [54]; it has been proposed that cholinergic signalling is mostly related to safe taste memories, whereas glutamatergic signalling is closely related to aversive memories [52-54]. We found that animals exposed to $500 \mu \mathrm{g} / \mathrm{kg} / \mathrm{day}$ of $\mathrm{MeHg}$ and trained at PND-40 showed no aversion to saccharin, suggesting a disruption in CTA acquisition, which could be due to impairment in glutamatergic signalling in the amygdala. In contrast, the MeHg-exposed animals that were trained at PND-90 demonstrated an aversion to saccharin, indicating no disturbances in CTA acquisition. However, the extinction rates for the $\mathrm{MeHg}$ and $\mathrm{MK}-801$ groups were faster than for the control group, which suggests that although these treatments were not able to attenuate aversion, as occurred with animals trained at PND-40, the aversive memories were easily forgotten. Interestingly, the $\mathrm{MeHg}$ effects on CTA were dose- and age-dependent, which suggests that this task was useful to evaluate the behavioural effect of gestational exposure to low-doses of MeHg. Kakita et al. [30] reported that gestational exposure to $1,000 \mu \mathrm{g} / \mathrm{kg} /$ day of $\mathrm{MeHg}$ decreased the neuronal population in the amygdala. In addition, amygdala functions are importantly related to anxiety behaviour, a characteristic that is related to low-dose prenatal MeHg exposure [18]. These effects should be studied further, particularly because no other study has assessed the effect of $\mathrm{MeHg}$ on aversive memories.

Overall, it is notable that the low-dose $\mathrm{MeHg}$ exposure was associated with adverse effects in the ORT, MWM, and CTA at PND-40, but at PND-90 only the spatial learning disturbance was observed. These findings could be due to an increased sensitivity or a preferential distribution of $\mathrm{MeHg}$ to the hippocampus. This brain region has been shown to be a potential target of $\mathrm{MeHg}$ accumulation [55] and its role in MWM performance has been widely studied. Thus, the results of this study point to the perirhinal cortex, hippocampus, and amygdala as brain areas that might be targets of gestational exposure to low-doses of $\mathrm{MeHg}$ because correct performance on the ORT, MWM, and CTA depends principally, although not exclusively, on these regions.

Our results for recognition memory, spatial learning, and aversive memories suggest a dose-dependent effect and consistently showed an age-dependent effect. That is, the $\mathrm{MeHg}$ effects are smaller when more time has passed between 
the last exposure and the evaluation of learning and memory. This could be due to the toxicokinetics of $\mathrm{MeHg}$ in the rat, resulting in reduced $\mathrm{MeHg}$ levels in the brain when exposure is terminated $[26,36]$. Hu et al. [36] demonstrated that after gestational exposure ended, the levels of $\mathrm{Hg}$ in the brains of rats peaked 18 days after the last administration; a decrease in $\mathrm{Hg}$ levels began one week after that, and $\mathrm{Hg}$ was almost undetectable 40 days after the exposure ended. In our study, exposure stopped at weaning, but the postnatal exposure was received through maternal milk, which promoted limited transport of $\mathrm{Hg}$ [26], permitting the $\mathrm{MeHg}$ brain levels to decrease to undetectable levels at PND-90. However, in other studies, even when $\mathrm{MeHg}$ was no longer detectable in the brain, the effects of previous exposure were permanent [24], most likely due to damage caused by high doses of $\mathrm{MeHg}(5,000 \mu \mathrm{g} / \mathrm{kg} \mathrm{MeHg})$ when it was present, such as cell death or inhibition of neuronal migration. Given the wide exposure schedule, there are different vulnerability windows of CNS development that could be disrupted by $\mathrm{MeHg}$ exposure [56]. The lowest level of exposure for which $\mathrm{MeHg}$ has been found to decrease DNA synthesis and neuronal number is in the range of 3,000 to $5,000 \mu \mathrm{g} / \mathrm{kg}[24,57]$. However, at the doses used in this study, the observed effects would depend on the presence of $\mathrm{MeHg}$, which has been reported to produce neurotransmission or synaptogenesis disturbances [56] associated with effects on learning and memory. Additionally, the differential age effects observed could be related to the increased susceptibility of younger organisms to deleterious effects of $\mathrm{MeHg}$ in the glutamatergic [58] and dopaminergic system [59], as well as to reactive oxygen species as reviewed in Farina et al. [60].

Although the experimental evidence indicates that the effects of developmental low-dose exposure to $\mathrm{MeHg}$ are subtle, it is important to mention that epidemiological studies have found detrimental effects on attention, learning, and memory in children exposed to "safe" levels of MeHg [61] at 7 years of age. These findings are in agreement with our results, suggesting that exposure to low-doses of $\mathrm{MeHg}$ is detrimental to cognitive processes at young ages. However, further studies are needed to determine whether the agedependent "subtle" effects found in our study are also agedependent in environmentally exposed populations.

It was notable that MK-801 (used to impair cognition) produced more pronounced effects at PND-40 than at PND90. The differences in the animals' behaviour may be related to age differences or the treatment schedule as has been demonstrated by Nilsson et al. [62], who reported that MK801 treatment does not increase the RI of animals.

\section{Conclusions}

Taken together, our results suggest that developmental lowdose exposure to $\mathrm{MeHg}$ disrupts memory and learning processes in a dose- and age-dependent manner and that if exposure stops at weaning, the effects observed at early life stages (PND-40 in rats, comparable to periadolescence in humans) will be subtle in later life (PND-90 in rats, comparable to young adulthood in humans). It is important to note that even when the exposed animals learned the different tasks in this study at PND-90, there was a delay in the correct performance of the MWM, which suggests a slight impairment in the acquisition of spatial learning.

In this study, the detrimental effects on behaviour were age-dependent, most likely because the exposure to lowdoses of $\mathrm{MeHg}$ was stopped after weaning; however, in human populations exposed to $\mathrm{MeHg}$, exposure does not stop at weaning, and, consequently, the adverse effects could be stronger than the effects observed in this study. The relevance of stopping exposure to $\mathrm{MeHg}$ after weaning in humans remains to be determined. These results may open a research field that could have relevance to establishing strategies to reduce the impact of in utero exposure to $\mathrm{MeHg}$ on learning and memory in humans.

\section{Abbreviations \\ CNS: Central nervous system \\ CTA: Conditioned taste aversion \\ GD: Gestational day \\ IQ: Intelligence Quotient \\ MeHg: Methylmercury \\ MWM: Morris water maze \\ NMDAR: N-Methyl D-aspartate receptor \\ OFT: $\quad$ Open field test \\ ORT: Object recognition test \\ PND: Postnatal day.}

\section{Conflict of Interests}

The authors declare that there is no conflict of interests.

\section{Acknowledgment}

This study was funded by a grant from the Mexican Council for Science and Technology (Conacyt 152491).

\section{References}

[1] M. Harada, "Congenital Minamata disease: intrauterine methylmercury poisoning," Teratology, vol. 18, no. 2, pp. 285-288, 1978.

[2] L. Amin-Zaki, M. A. Majeed, M. R. Greenwood, S. B. Elhassani, T. W. Clarkson, and R. A. Doherty, "Methylmercury poisoning in the Iraqi suckling infant: a longitudinal study over five years," Journal of Applied Toxicology, vol. 1, no. 4, pp. 210-214, 1981.

[3] T. Yorifuji, T. Kato, Y. Kado et al., "Intrauterine exposure to methylmercury and neurocognitive functions: minamata disease," Archives of Environmental and Occupational Health Journal, vol. 70, no. 5, pp. 297-302, 2015.

[4] P. W. Davidson, A. Leste, E. Benstrong et al., "Fish consumption, mercury exposure, and their associations with scholastic achievement in the Seychelles Child Development Study," NeuroToxicology, vol. 31, no. 5, pp. 439-447, 2010.

[5] D. A. Axelrad, D. C. Bellinger, L. M. Ryan, and T. J. Woodruff, "Dose-response relationship of prenatal mercury exposure and IQ: an integrative analysis of epidemiologic data," Environmental Health Perspectives, vol. 115, no. 4, pp. 609-615, 2007. 
[6] M. R. Karagas, A. L. Choi, E. Oken et al., "Evidence on the human health effects of low-level methylmercury exposure," Environmental Health Perspectives, vol. 120, no. 6, pp. 799-806, 2012.

[7] T. A. Seabert, S. Pal, B. M. Pinet et al., "Elevated contaminants contrasted with potential benefits of $\omega$-3 fatty acids in wild food consumers of two remote first nations communities in Northern Ontario, Canada," PLoS ONE, vol. 9, no. 3, Article ID e90351, 2014.

[8] L. Trasande, J. E. Cortes, P. J. Landrigan, M. I. Abercrombie, R. F. Bopp, and E. Cifuentes, "Methylmercury exposure in a subsistence fishing community in Lake Chapala, Mexico: an ecological approach," Environmental Health, vol. 9, article 1, 2010.

[9] M. C. Sheehan, T. A. Burke, A. Navas-Acien, P. N. Breysse, J. McGready, and M. A. Fox, "Global methylmercury exposure from seafood consumption and risk of developmental neurotoxicity: a systematic review," Bulletin of the World Health Organization, vol. 92, no. 4, pp. 254F-269F, 2014.

[10] A. M. Schaefer, E. L. Jensen, G. D. Bossart, and J. S. Reif, "Hair mercury concentrations and fish consumption patterns in Florida residents," International Journal of Environmental Research and Public Health, vol. 11, no. 7, pp. 6709-6726, 2014.

[11] T. C. D. O. Corvelo, É. A. F. Oliveira, A. M. de Parijós et al., "Monitoring mercury exposure in reproductive aged women inhabiting the Tapajós River Basin, Amazon," Bulletin of Environmental Contamination and Toxicology, vol. 93, no. 1, pp. 4246, 2014.

[12] J. L. Guentzel, E. Portilla, K. M. Keith, and E. O. Keith, "Mercury transport and bioaccumulation in riverbank communities of the Alvarado Lagoon System, Veracruz State, Mexico," Science of the Total Environment, vol. 388, no. 1-3, pp. 316-324, 2007.

[13] L. Trasande, P. J. Landrigan, and C. Schechter, "Public health and economic consequences of methyl mercury toxicity to the developing brain," Environmental Health Perspectives, vol. 113, no. 5, pp. 590-596, 2005.

[14] M. Bellanger, C. Pichery, D. Aerts et al., "Economic benefits of methylmercury exposure control in Europe: monetary value of neurotoxicity prevention," Environmental Health, vol. 12, article 3, 2013.

[15] T. M. Burbacher, G. P. Sackett, and N. K. Mottet, "Methylmercury effects on the social behavior of Macaca fascicularis infants," Neurotoxicology and Teratology, vol. 12, no. 1, pp. 6571, 1990.

[16] V. M. Gunderson, K. S. Grant, T. M. Burbacher, J. F. Fagan III, and N. K. Mottet, "The effect of low-level prenatal methylmercury exposure on visual recognition memory in infant crabeating macaques," Child Development, vol. 57, no. 4, pp. 10761083, 1986.

[17] V. M. Gunderson, K. S. Grant-Webster, T. M. Burbacher, and N. K. Mottet, "Visual recognition memory deficits in methylmercury-exposed Macaca fascicularis infants," Neurotoxicology and Teratology, vol. 10, no. 4, pp. 373-379, 1988.

[18] N. Onishchenko, C. Tamm, M. Vahter et al., "Developmental exposure to methylmercury alters learning and induces depression-like behavior in male mice," Toxicological Sciences, vol. 97, no. 2, pp. 428-437, 2007.

[19] A. F. Castoldi, N. Onishchenko, C. Johansson et al., "Neurodevelopmental toxicity of methylmercury: laboratory animal data and their contribution to human risk assessment," Regulatory Toxicology and Pharmacology, vol. 51, no. 2, pp. 215-229, 2008.
[20] E. Cernichiari, R. Brewer, G. J. Myers et al., "Monitoring methylmercury during pregnancy: maternal hair predicts fetal brain exposure," Neurotoxicology, vol. 16, no. 4, pp. 705-710, 1995.

[21] C. U. Eccles and Z. Annau, The Toxicity of Methyl Mercury, Johns Hopkins University Press, Baltimore, Md, USA, 1987.

[22] A. Rossi, Molecular mechanisms of metal toxicity in neuronal cells [Ph.D. dissertation], Karolinska Institutet, Stockholm, Sweden, 1996.

[23] M. Sakamoto, A. Kakita, R. B. de Oliveira, H. S. Pan, and H. Takahashi, "Dose-dependent effects of methylmercury administered during neonatal brain spurt in rats," Developmental Brain Research, vol. 152, no. 2, pp. 171-176, 2004.

[24] A. Falluel-Morel, K. Sokolowski, H. M. Sisti, X. Zhou, T. J. Shors, and E. DiCicco-Bloom, "Developmental mercury exposure elicits acute hippocampal cell death, reductions in neurogenesis, and severe learning deficits during puberty," Journal of Neurochemistry, vol. 103, no. 5, pp. 1968-1981, 2007.

[25] J. Cheng, M. Fujimura, W. Zhao, and W. Wang, "Neurobehavioral effects, c-Fos/Jun expression and tissue distribution in rat offspring prenatally co-exposed to $\mathrm{MeHg}$ and PFOA: PFOA impairs Hg retention," Chemosphere, vol. 91, no. 6, pp. 758-764, 2013.

[26] M. Sakamoto, A. Kakita, K. Wakabayashi, H. Takahashi, A. Nakano, and H. Akagi, "Evaluation of changes in methylmercury accumulation in the developing rat brain and its effects: a study with consecutive and moderate dose exposure throughout gestation and lactation periods," Brain Research, vol. 949, no. 12, pp. 51-59, 2002.

[27] C. S. Roegge, V. C. Wang, B. E. Powers et al., "Motor impairment in rats exposed to PCBs and methylmercury during early development," Toxicological Sciences, vol. 77, no. 2, pp. 315-324, 2004.

[28] N. N. Karpova, J. S. O. Lindholm, N. Kulesskaya et al., “TrkB overexpression in mice buffers against memory deficits and depression-like behavior but not all anxiety- and stress-related symptoms induced by developmental exposure to methylmercury," Frontiers in Behavioral Neuroscience, vol. 8, article 315, 2014.

[29] M. Obiorah, E. McCandlish, B. Buckley, and E. DiCicco-Bloom, "Hippocampal developmental vulnerability to methylmercury extends into prepubescence," Frontiers in Neuroscience, vol. 9, article 150, 2015.

[30] A. Kakita, K. Wakabayashi, M. Su et al., "Intrauterine methylmercury intoxication. Consequence of the inherent brain lesions and cognitive dysfunction in maturity," Brain Research, vol. 877, no. 2, pp. 322-330, 2000.

[31] B. Weiss, S. Stern, C. Cox, and M. Balys, "Perinatal and lifetime exposure to methylmercury in the mouse: behavioral effects," NeuroToxicology, vol. 26, no. 4, pp. 675-690, 2005.

[32] R. J. Katz, K. A. Roth, and B. J. Carroll, "Acute and chronic stress effects on open field activity in the rat: implications for a model of depression," Neuroscience and Biobehavioral Reviews, vol. 5, no. 2, pp. 247-251, 1981.

[33] C. V. Vorhees and M. T. Williams, "Morris water maze: procedures for assessing spatial and related forms of learning and memory," Nature Protocols, vol. 1, no. 2, pp. 848-858, 2006.

[34] K. Rosenblum, N. Meiri, and Y. Dudai, “Taste memory: the role of protein synthesis in gustatory cortex," Behavioral and Neural Biology, vol. 59, no. 1, pp. 49-56, 1993.

[35] T. M. Burbacher, P. M. Rodier, and B. Weiss, "Methylmercury developmental neurotoxicity: a comparison of effects in 
humans and animals," Neurotoxicology and Teratology, vol. 12, no. 3, pp. 191-202, 1990.

[36] G. Hu, M. Jin, X. Lin, C. Guo, L. Zhang, and Z. Sun, "Mercury distribution in neonatal rat brain after intrauterine methylmercury exposure," Environmental Toxicology and Pharmacology, vol. 29, no. 1, pp. 7-11, 2010.

[37] A. Ennaceur and J. Delacour, "A new one-trial test for neurobiological studies of memory in rats. 1: behavioral data," Behavioural Brain Research, vol. 31, no. 1, pp. 47-59, 1988.

[38] P. Grandjean, P. Weihe, R. F. White et al., "Cognitive deficit in 7-year-old children with prenatal exposure to methylmercury," Neurotoxicology and Teratology, vol. 19, no. 6, pp. 417-428, 1997.

[39] M. R. Carratù, P. Borracci, A. Coluccia et al., "Acute exposure to methylmercury at two developmental windows: focus on neurobehavioral and neurochemical effects in rat offspring," Neuroscience, vol. 141, no. 3, pp. 1619-1629, 2006.

[40] M. Baraldi, P. Zanoli, F. Tascedda, J. M. C. Blom, and N. Brunello, "Cognitive deficits and changes in gene expression of NMDA receptors after prenatal methylmercury exposure," Environmental Health Perspectives, vol. 110, supplement 5, pp. 855-858, 2002.

[41] E. Fonfría, M. T. Vilaró, Z. Babot, E. Rodríguez-Farré, and C. Suñol, "Mercury compounds disrupt neuronal glutamate transport in cultured mouse cerebellar granule cells," Journal of Neuroscience Research, vol. 79, no. 4, pp. 545-553, 2005.

[42] F. Debes, E. Budtz-Jørgensen, P. Weihe, R. F. White, and P. Grandjean, "Impact of prenatal methylmercury exposure on neurobehavioral function at age 14 years," Neurotoxicology and Teratology, vol. 28, no. 5, pp. 536-547, 2006.

[43] O. Boucher, C. H. Bastien, D. Saint-Amour et al., "Prenatal exposure to methylmercury and PCBs affects distinct stages of information processing: an event-related potential study with Inuit children," NeuroToxicology, vol. 31, no. 4, pp. 373-384, 2010 .

[44] O. Boucher, S. W. Jacobson, P. Plusquellec et al., "Prenatal methylmercury, postnatal lead exposure, and evidence of attention deficit/hyperactivity disorder among Inuit children in Arctic Québec," Environmental Health Perspectives, vol. 120, no. 10, pp. 1456-1461, 2012.

[45] E. Oken, R. O. Wright, K. P. Kleinman et al., "Maternal fish consumption, hair mercury, and infant cognition in a U.S. cohort," Environmental Health Perspectives, vol. 113, no. 10, pp. 1376-1380, 2005.

[46] E. Cernichiari, T. Y. Toribara, L. Liang et al., "The biological monitoring of mercury in the Seychelles study," NeuroToxicology, vol. 16, no. 4, pp. 613-628, 1995.

[47] G. J. Myers, P. W. Davidson, C. F. Shamlaye et al., "Effects of prenatal methylmercury exposure from a high fish diet on developmental milestones in the Seychelles Child Development Study," Neurotoxicology, vol. 18, no. 3, pp. 819-830, 1997.

[48] P. W. Davidson, G. J. Myers, B. Weiss, C. F. Shamlaye, and C. Cox, "Prenatal methyl mercury exposure from fish consumption and child development: a review of evidence and perspectives from the Seychelles Child Development Study," NeuroToxicology, vol. 27, no. 6, pp. 1106-1109, 2006.

[49] K. Sokolowski, M. Obiorah, K. Robinson, E. Mccandlish, B. Buckley, and E. Dicicco-Bloom, "Neural stem cell apoptosis after low-methylmercury exposures in postnatal hippocampus produce persistent cell loss and adolescent memory deficits," Developmental Neurobiology, vol. 73, no. 12, pp. 936-949, 2013.

[50] W. Liu, X. Wang, R. Zhang, and Y. Zhou, "Effects of postnatal exposure to methylmercury on spatial learning and memory and brain NMDA receptor mRNA expression in rats," Toxicology Letters, vol. 188, no. 3, pp. 230-235, 2009.

[51] F. Bermúdez-Rattoni, "Molecular mechanisms of taste-recognition memory," Nature Reviews Neuroscience, vol. 5, no. 3, pp. 209-217, 2004.

[52] H. Gutiérrez, E. Hernández-Echeagaray, V. Ramírez-Amaya, and F. Bermúdez-Rattoni, "Blockade of N-methyl-D-aspartate receptors in the insular cortex disrupts taste aversion and spatial memory formation," Neuroscience, vol. 89, no. 3, pp. 751-758, 1999.

[53] G. Ferreira, R. Gutiérrez, V. De La Cruz, and F. BermúdezRattoni, "Differential involvement of cortical muscarinic and NMDA receptors in short- and long-term taste aversion memory," European Journal of Neuroscience, vol. 16, no. 6, pp. 1139$1145,2002$.

[54] Y. Yasoshima, T. Morimoto, and T. Yamamoto, "Different disruptive effects on the acquisition and expression of conditioned taste aversion by blockades of amygdalar ionotropic and metabotropic glutamatergic receptor subtypes in rats," Brain Research, vol. 869, no. 1-2, pp. 15-24, 2000.

[55] J.-P. Bourdineaud, M. Marumoto, A. Yasutake, and M. Fujimura, "Dietary mercury exposure resulted in behavioral differences in mice contaminated with fish-associated methylmercury compared to methylmercury chloride added to diet," Journal of Biomedicine and Biotechnology, vol. 2012, Article ID 681016, 9 pages, 2012.

[56] D. Rice and S. Barone Jr., "Critical periods of vulnerability for the developing nervous system: evidence from humans and animal models," Environmental Health Perspectives, vol. 108, supplement 3, pp. 511-533, 2000.

[57] K. Burke, Y. Cheng, B. Li et al., "Methylmercury elicits rapid inhibition of cell proliferation in the developing brain and decreases cell cycle regulator, cyclin E," NeuroToxicology, vol. 27, no. 6, pp. 970-981, 2006.

[58] B. Rajanna, S. Rajanna, E. Hall, and P. R. Yallapragada, "In vitro metal inhibition of N-methyl-D-aspartate specific glutamate receptor binding in neonatal and adult rat brain," Drug and Chemical Toxicology, vol. 20, no. 1-2, pp. 21-29, 1997.

[59] A. Dreiem, M. Shan, R. J. Okoniewski, S. Sanchez-Morrissey, and R. F. Seegal, "Methylmercury inhibits dopaminergic function in rat pup synaptosomes in an age-dependent manner," Neurotoxicology and Teratology, vol. 31, no. 5, pp. 312-317, 2009.

[60] M. Farina, J. B. T. Rocha, and M. Aschner, "Mechanisms of methylmercury-induced neurotoxicity: evidence from experimental studies," Life Sciences, vol. 89, no. 15-16, pp. 555-563, 2011.

[61] P. Grandjean, P. Weihe, R. F. White, and F. Debes, "Cognitive performance of children prenatally exposed to 'safe' levels of methylmercury," Environmental Research, vol. 77, no. 2, pp. 165172, 1998.

[62] M. Nilsson, S. Hansson, A. Carlsson, and M. L. Carlsson, "Differential effects of the $N$-methyl-D-aspartate receptor antagonist MK-801 on different stages of object recognition memory in mice," Neuroscience, vol. 149, no. 1, pp. 123-130, 2007. 

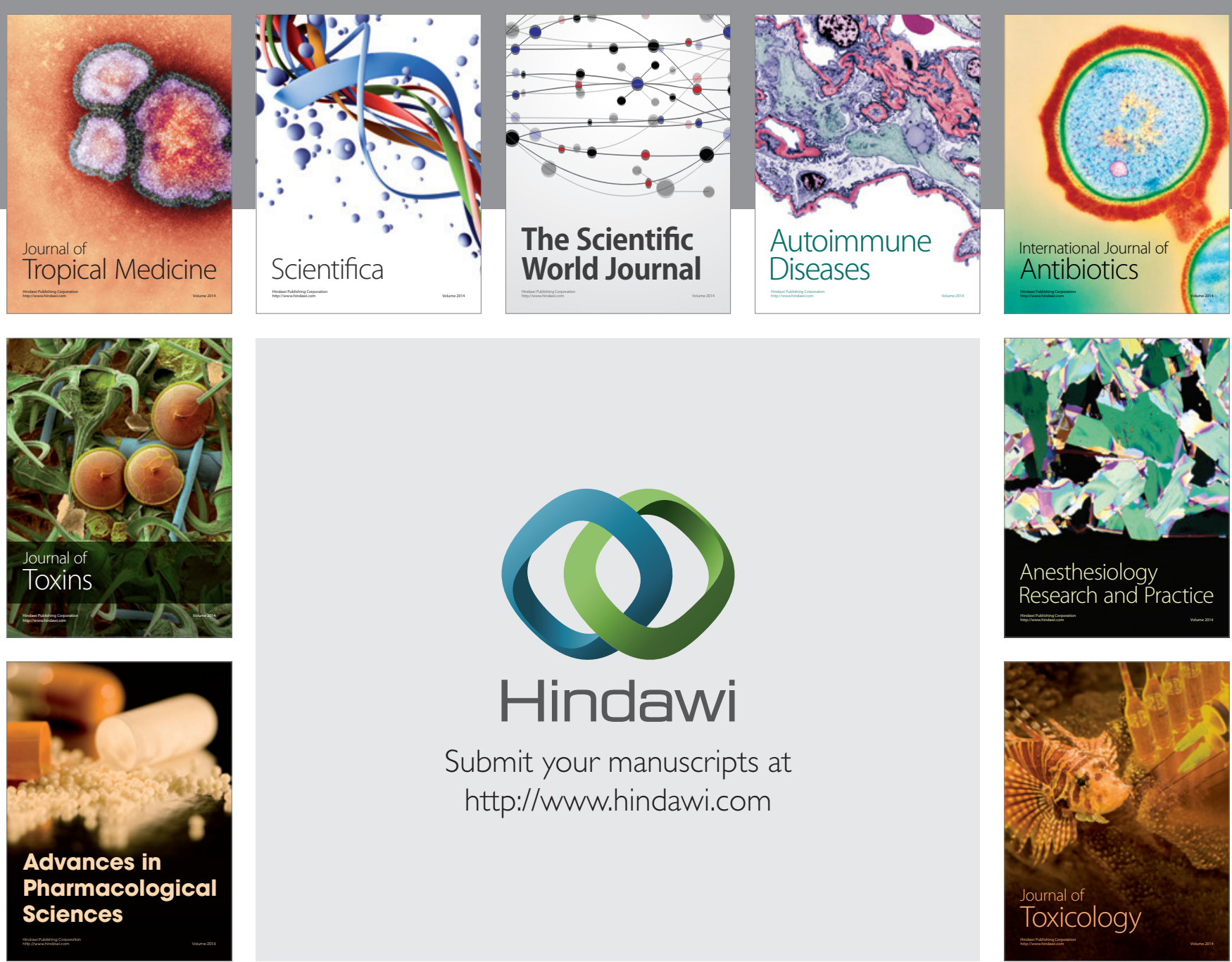

\section{Hindawi}

Submit your manuscripts at

http://www.hindawi.com
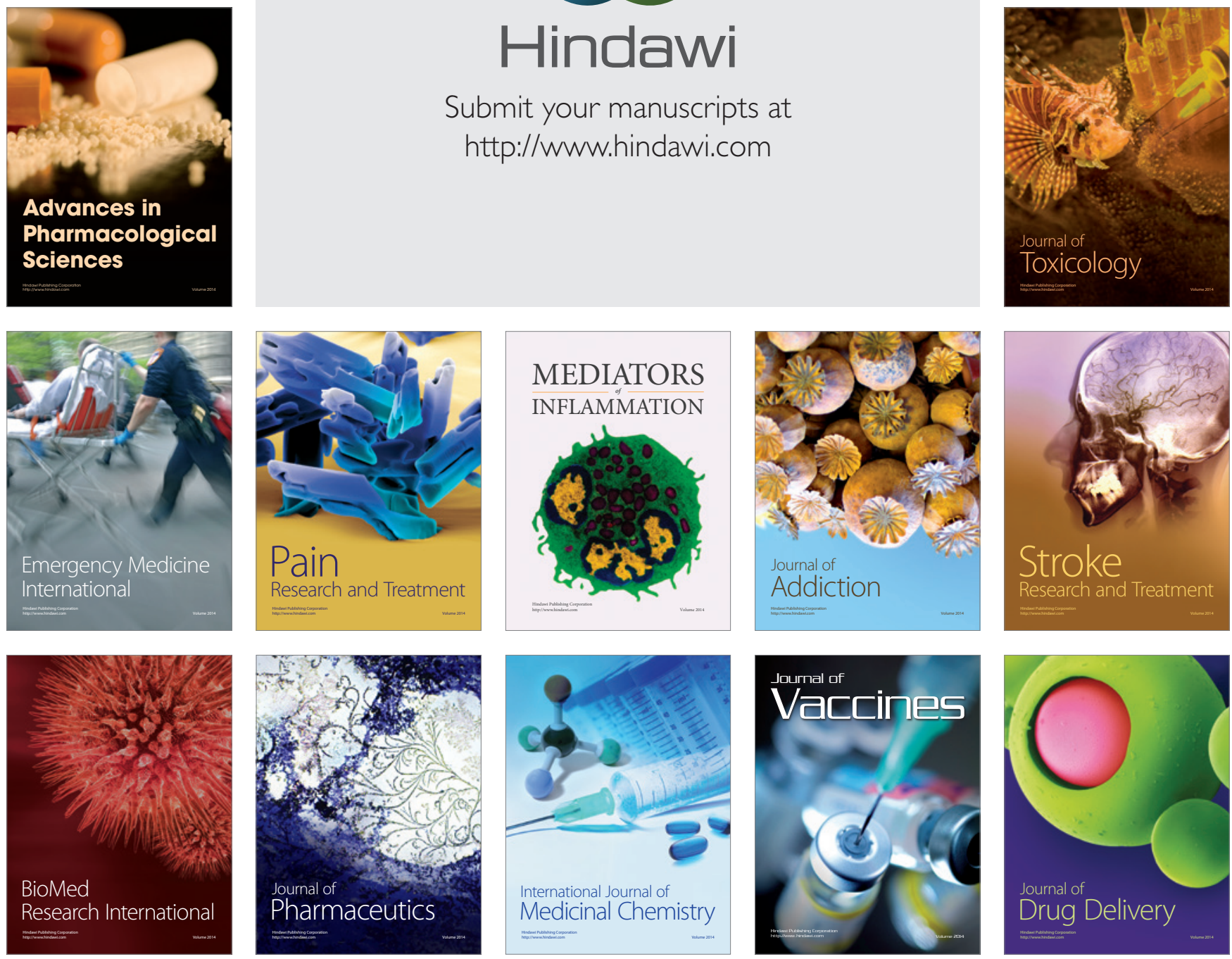